\title{
Cranial Cavity
}

National Cancer Institute

\section{Source}

National Cancer Institute. Cranial Cavity. NCI Thesaurus. Code C77638.

The atrium that is formed by the bones of the skull and containing the brain. 